\title{
Obtaining zeolites from slags and ashes from a waste combustion plant in an autoclave process
}

\author{
Agnieszka Grela ${ }^{1, *}$, Michat $\mathrm{Lach}^{2}$, Dariusz Mierzwiński ${ }^{2}$, Tomasz Bajda ${ }^{3}$, \\ and Janusz Mikuła ${ }^{2}$ \\ ${ }^{1}$ Cracow University of Technology, Faculty of Environmental Engineering, Institute of Engineering \\ and Water Management, Warszawska 24, 31-151 Cracow, Poland \\ ${ }^{2}$ Cracow University of Technology, Faculty of Mechanical Engineering, Institute of Materials \\ Engineering, 37 Jana Pawła II Av., 31-864 Cracow, Poland \\ ${ }^{3}$ AGH University of Science and Technology in Kraków, Faculty of Geology, Geophysics and \\ Environmental Protection, Department of Mineralogy, Petrography and Geochemistry, 30 \\ Mickiewicza Av., 30-059 Cracow, Poland
}

\begin{abstract}
Waste combustion is associated with the generation of postprocessing solid products - waste such as slag and ash. One of the promising technologies in waste management and processing is the synthesis of zeolites and other materials exhibiting sorption properties. The aim of this study was to characterise and assess the physicochemical properties of the waste and the products synthesised from it. This paper presents the possibility of synthesis zeolites from the slag and ash from two waste combustion plants. The investigated waste is classified as hazardous waste and denoted by the EWC code 190111*. The paper presents the results of physicochemical studies of these materials. As a result of synthesis in an autoclave at $140^{\circ} \mathrm{C}$ with the use of $2 \mathrm{M} \mathrm{NaOH}$, and other compounds, such zeolite forms as chabazite and sodalite were obtained. Textural studies and ion-exchange capacity investigations carried out allowed characterisation of the sorption properties of the materials. It was found that the materials obtained are characterised by the BET specific surface areas of $25.45 \mathrm{~m}^{2} / \mathrm{g}$ and $16.79 \mathrm{~m}^{2} / \mathrm{g}$.
\end{abstract}

\section{Introduction}

Waste combustion is a method that is a universally applied element of the waste management system in European Union countries. Incineration allows solid and liquid waste neutralisation that is safe for the environment and guarantees that all the requirements for the inertness of an ecological waste incineration plant are fulfilled [1]. Using the thermal neutralisation method, it is feasible to reduce the waste amount, but also to recover and use their intrinsic energy. At present, it is possible to reduce the waste volume up from to $80 \%$ (without slag processing) to $94 \%$ (with slag processing). Considering the weight of

*Corresponding author: agrela@pk.edu.pl 
the waste, it is possible to reduce it from $60 \%$ to $70 \%$ [2]. The residues from waste incineration are fly ash and slag, or ash-slag mixtures and the like, so-called, waste. To correctly select the waste management and neutralisation method, above all their properties should be determined accurately. Most often, the following tests are performed: phase composition characterisation (XRD), chemical composition analysis, aqueous leaching testing, fineness and moisture content determination, morphology evaluation (SEM), pore size distribution and specific surface area measurements (BET, BJH), as well as, cation and anion exchange capacity determination (CEC and AEC) [3]. The results of studies carried out allow the basic ways of using the waste to be defined.

One of the promising technologies concerning the management and processing of the waste from waste incineration plants is the synthesis of zeolites and other materials exhibiting sorption properties [4]. Zeolites are crystalline aluminosilicate compounds with a highly developed inner structure $[5,6]$ with a characteristic channel structure, in which the channels are interlinked with $\mathrm{SiO} 4$ and $\mathrm{AlO} 4$ tetrahedra. This makes them very good sorbents, catalysts and ion-exchange materials [7]. In nature, molecular sieves that allow the formation of zeolites, are generally formed upon passing of geothermally heated water through silicate volcanic ash. Due to the high demand of the industry for synthetic zeolites, methods for producing these materials economically are still sought after. Initially, volcanic ash was used as starting material, and for the synthesis, hydrothermal reactions at elevated temperatures $\left(50-105^{\circ} \mathrm{C}\right)$ were employed. In recent years, the feasibility of using fly ashes from hard coal and brown coal was successfully studied [8-14] as well as the ash from fluid boilers $[15,16]$ for the synthesis of zeolite materials. Initial approaches to the synthesis of zeolites focused on the replication of the high pressure and temperature conditions that occur in nature. Barrer (J. Chem. Soc., 1948, page 127) presented the first successful zeolite synthesis, and Milton (US Patent 2882243 (1959)) developed a large scale synthesis of zeolites under low temperature and pressure conditions, which made it possible to gain industrial importance. Owing to intense studies, it is possible to discover new zeolite structures and to obtain thorough knowledge of their properties.

All over the world, an increasing amount of scientific research is conducted on this subject. Ash from waste incinerators may be used as the starting material for the synthesis of zeolites such as: gismondine or gmelite [17, 18] zeolite A and zeolite P [18-21]. It is also possible to obtain zeolite materials from the waste incineration slag [22] in this way, e.g., tobermorite and hydrated sodium aluminium silicates were obtained that exhibited the BET specific surface area of $22.1 \mathrm{~m}^{2} / \mathrm{g}$ (compared with $4.6 \mathrm{~m}^{2} / \mathrm{g}$ for the starting material). The studies showed the suitability of the materials obtained for the adsorption of heavy metal cations. Zeolites produced from fly ash from waste incineration may be employed for the removal of cadmium, chromium and lead ions [23-26]. Other investigations [27] demonstrated that ash from wastewater sludge incineration may be used as a filter filler for the treatment of phosphorus containing wastewaters.

The aim of this study was to characterise and assess the physicochemical properties of the waste such as slag and ash from waste incineration and to characterise the synthesis products formed in the autoclaving process.

\section{Experiments}

\subsection{Materials}

Two waste types (waste from diagnosis, treatment and medical prevention and industrial waste produced in factories) with the EWC code $190111^{*}$ - Bottom ash and slag containing 
dangerous substances, from two waste incineration plants in Poland, were subjected to study. Table 1 presents the designation of material samples used in the studies.

Table 1. Designations of samples of the materials used in the study.

\begin{tabular}{|c|c|}
\hline Sample & Description \\
\hline W1 & $\begin{array}{c}190111^{*} \text { - Bottom ash and slag containing dangerous } \\
\text { substances. Industrial and medical waste incineration plant }\end{array}$ \\
\hline W1A & W1 after autoclaving process $\left(2 \mathrm{M} \mathrm{NaOH}, 140^{\circ} \mathrm{C}, 6 \mathrm{~h}\right)$ \\
\hline W2 & $\begin{array}{c}190111^{*}-\text { Bottom ash and slag containing dangerous } \\
\text { substances. Industrial and hazardous waste incineration plant }\end{array}$ \\
\hline W2A & W2 after autoclaving process $\left(2 \mathrm{M} \mathrm{NaOH}, 140^{\circ} \mathrm{C}, 6 \mathrm{~h}\right)$ \\
\hline
\end{tabular}

\subsection{Syntheses in autoclave}

The synthesis process was carried out in a PARR pressurised chemical reactor (autoclave). The post-processing waste from the thermal conversion of the waste denoted as $190111^{*}$ - Bottom ash and slag containing dangerous substances was charged into the reactor, then $2 \mathrm{M} \mathrm{NaOH}$ solution was added to an amount of $1000 \mathrm{ml}$ per $250 \mathrm{~g}$ of waste. The mixture thus prepared was closed in the chemical reactor, in which the pressure was increased up to the level of $0.5 \mathrm{MPa}$. Next, after 5 minutes, the mixture was heated up to $140^{\circ} \mathrm{C}$ at a rate of $2^{\circ} \mathrm{C} / \mathrm{min}$, while the working pressure in the reactor was concurrently raised. The heating time at the reaction temperature was equal to $6 \mathrm{~h}$, and the working pressure was 1.1 $\mathrm{MPa}$. After heating, the reaction system was cooled down at a rate of $0.3^{\circ} \mathrm{C} / \mathrm{min}$. The total processing time was $24 \mathrm{~h}$.

Afterwards, the $\mathrm{NaOH}$ solution used for the synthesis was removed (by decanting the liquid from above the sediment) into an appropriate container. The obtained reaction mixture was placed in a vessel with water warmed up to $30^{\circ} \mathrm{C}$. To wash the mixture, a POLSONIC ultrasonic washer was employed. The washing was carried out for $30 \mathrm{~min}$. After the washings were poured out, the reaction mixture was washed with water until the $\mathrm{pH}$ of the washings did not fall below 9. Next, the reaction mixture was dried at a temperature of $100^{\circ} \mathrm{C}$ for $12 \mathrm{~h}$.

\subsection{Examination methods}

The phase composition of samples W1, W2, W1A and W2A were determined using powder X-ray diffraction Debye-Scherrer-Hull method. Diffractograms of samples W1, W2, W1A and W2A were recorded with the use of a Rigaku SmartLab X-ray diffractometer using the following parameters: $\mathrm{CuK} \alpha$ radiation, a graphite reflection monochromator, tube voltage $45 \mathrm{kV}$, tube current 200, step scan mode: step size $=0.05^{\circ} 2 \theta$, per $1 \mathrm{~s}$. The values of interplanar distances were used for the identification of phases present in the samples based on data contained in the ICDD (International Centre for Diffraction Data 2014) Catalogue and XRAYAN software. For samples W1 and W2, their chemical composition was determined. The analyses were carried out with the use of a XRF WDX PANalytical Spectrometer.

The dioxin content was determined with gas chromatography coupled with mass spectrometry (GC-MS/MS) in the Laboratory of Trace Analysis at the Cracow University of Technology. The examination was carried out according to the $\mathrm{P} / 01 / 03$ procedure imposed on 1103 2010. The results were expressed as the upper limit of TEQ (Toxic Equivalency) according to the I-TEF (1988). 
Aqueous leaching tests were performed in the Mo-BRUK S.A. accredited laboratory in accordance with PN-EN 12457-4:2006. Samples for the determination of metal content were prepared according to PN-EN ISO 15587-2:2005. Depending on the type of substance analysed, one of the following methods was used: gravimetry, spectrophotometry, ionchromatography, Inductively Coupled Plasma - Optical Emission Spectrometry (ICPOES). The masses of the analysed samples were of ca. $2.5 \mathrm{~kg}$ each. Single-stage, batch test, at liquid to solid phase ratio of $10 \mathrm{l} / \mathrm{kg}$ in the case of below $10 \mathrm{~mm}$ grain-size materials (without size reduction or with size reduction).

Fineness testing was carried out in accordance with EN 451-2 by wet sieving. Moisture content was determined in delivered conditions by an analytical method of drying the ash in a moisture analyser (Radwag MAC50/1/NH) to constant mass.

The morphology of samples was studied with a JEOL JSM-820 scanning microscope. Samples were beforehand appropriately prepared. Small quantities of materials were dried to constant mass, and next, they were placed on a carbon substrate that ensures removing the charge from the sample. The materials were coated with a thin layer of gold by a JEOL JEE-4X Vacuum Evaporator.

Porosity and specific surface area measurements were performed with the use of a BETASAP 2020 Accelerated Surface Area and Porosimetry Analyser. Samples were degassed at a temperature of $373 \mathrm{~K}$ for $24 \mathrm{~h}$. To determine the distribution of pore volume function in the materials analysed, experimental low-temperature $(77 \mathrm{~K})$ nitrogen adsorption isotherms were used. The Barrett-Joyner-Halenda (BJH) method was employed, and to determine the specific surface area, the Brunauer-Emmett-Taller (BET) method was applied.

Cation Exchange Capacity (CEC) was determined with the $\mathrm{NH}_{4}$ sorption-desorption method. Anion Exchange Capacity (AEC) was determined with the phosphate method [28].

\section{Results and discussion}

\subsection{Materials before autoclaving}

Figure. $1 \mathrm{a}$ and $\mathrm{b}$ present the recorded diffractograms of the waste samples, W1 and W2, respectively. Based on the analysis of the diffraction spectrum it was found that in sample W1 the following phases are present: plagioclase, wollastonite, goethite, maghemite, hematite, calcite, quartz (Fig. 1a), while in sample W2, the following phases were identified: clinochlore, calcite, plagioclase, wollastonite, gehlenite (Fig. 1b).
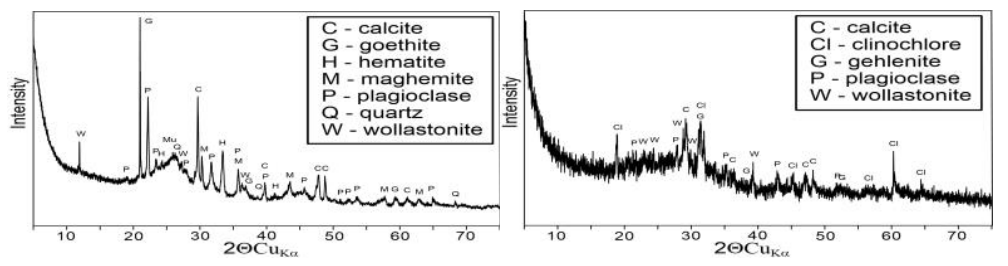

Fig. 1. X-ray diffraction pattern of samples: W1 (left) and W2 (right).

Table 2 presents the chemical composition analysis results for the waste samples. The dominating components are $\mathrm{SiO}_{2}$ and $\mathrm{Al}_{2} \mathrm{O}_{3}$ that are of key importance for the processes of zeolite production. $\mathrm{CaO}$ (14-15 wt.\%) adversely affects the process of zeolite phase formation. The $\mathrm{SiO}_{2}$ and $\mathrm{Al}_{2} \mathrm{O}_{3}$ contents are similar in both waste samples (about 50\%).

Table 3 presents the results of dioxin content analyses. The result is expressed as standardised toxic equivalency TEQ according to I-TEF od 1988 and presented as its upper limit. The total dioxin content of the W2 ash is almost fourfold higher compared to that of the W1 ash. Despite such differences, the dioxin content of both wastes is at a low level. In 
Poland, there are no regulations concerning dioxin and furan emissions from waste incineration and their content of ashes and slags is not determined routinely.

Table 2. The chemical composition [wt. \%] of samples W1 and W2 used in study.

\begin{tabular}{|c|c|c|c|c|c|c|c|c|}
\hline Sample & $\mathbf{S i O}_{\mathbf{2}}$ & $\mathbf{T i O}_{\mathbf{2}}$ & $\mathbf{A l}_{\mathbf{2}} \mathbf{O}_{\mathbf{3}}$ & $\mathbf{F e}_{\mathbf{2}} \mathbf{O}_{\mathbf{3}}$ & $\mathbf{N a}_{\mathbf{2}} \mathbf{O}$ & $\mathbf{K}_{\mathbf{2}} \mathbf{O}$ & $\mathbf{C a O}$ & $\mathbf{M g O}$ \\
\hline $\mathrm{W} 1$ & 38.02 & 2.02 & 10.50 & 6.25 & 4.84 & 0.51 & 15.39 & 1.49 \\
\hline $\mathrm{W} 2$ & 36.61 & 3.29 & 8.95 & 16.45 & 11.08 & 0.61 & 14.22 & 1.80 \\
\hline
\end{tabular}

Setting out dioxin emission standards would result in the necessity of carrying out appropriate controls. Dioxin emission testing is very costly and only a few research centres in Poland are able to take on the task of determining the dioxin concentration [29].

The toxicity of the ash and slag may be compared with the pollution limit values that are used for the ground or soil. A total dioxin content less than $0.005 \mathrm{ng} / \mathrm{g}$ allows the area to be used for agricultural purposes without any limitations. If the total dioxin content is in the range of $0.04-0.1 \mathrm{ng} / \mathrm{g}$, then, it is permitted to use the area for fruit and shrub growing (however, with dioxin content control of other products), as well as for playing grounds for children. A total dioxin content in the range of $0.1-1.0 \mathrm{ng} / \mathrm{g}$ results in total unsuitability of the material for use in agriculture and horticulture, and it must be replaced [29] (Table 3).

Table 3 also shows selected physical properties of the waste samples. The test results are significant for their technological importance. They affect the alkaline activation process with respect to their water demand. Water demand depends on the moisture content level and their grain size (fineness). The drier and smaller the grains, the higher the absorptivity of the liquid activator. It was found that the studied waste samples differed slightly in their fineness, meant as the sieve residue (aperture size $0.045 \mu \mathrm{m}$ ) at wet sieving. The results obtained show that the differences in grain sizes of the tested waste samples are small.

Table 3. Results of the determination of dioxin content of studied wastes from incineration plants and results of physical properties testing of waste samples.

\begin{tabular}{|c|c|c|c|}
\hline Sample & $\begin{array}{c}\text { Total dioxin content } \\
\text { (I-PCDD/F-TEQ) [ng/g] }\end{array}$ & Fineness [\%] & Moisture [\%] \\
\hline W1 & $0.20 \pm 0.053$ & $69.74 \pm 1.29$ & $28.30 \pm 2.74$ \\
\hline W2 & $0.057 \pm 0.015$ & $58.73 \pm 0.48$ & $0.42 \pm 0.04$ \\
\hline
\end{tabular}

For samples W1 and W2 aqueous leaching tests was performed. Based on the results obtained it was found that high amounts of chloride and barium ions undergo leaching from the W1 waste, whereas the W2 waste contains an elevated amount of fluorides. The content of Total Dissolved Solids (TDS) of about $7000 \mathrm{mg} / \mathrm{kg}$ is at a similar level for both wastes. Samples W1 and W2 contain the same amount of hexavalent chromium, $\mathrm{Cr}^{6+}$.

Fig. 2 shows the morphology of the waste samples. Different grain and crystalline forms were observed that were characteristic of a given waste type. In sample W1, agglomerate forming plate-shaped grains and rods glued together were observed. Waste sample W2 is characterised by single, irregular particles of the size above 100-200 $\mu \mathrm{m}$. Their edges are sharp and their surfaces non-uniform, with visible hollows.
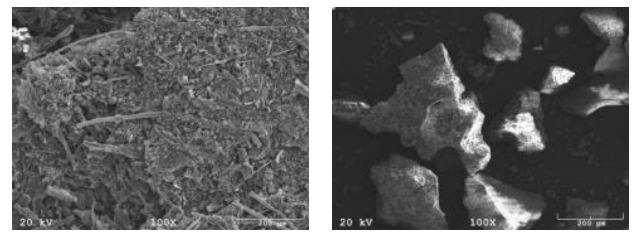

Fig. 2. SEM images of samples W1 (left) and W2 (right). Magnification 100x. 
Textural parameters were determined for samples W1 and W2 (Table 4). Both samples had a type II isotherm with a hysteresis loop of type H3. This corresponds to a mesoporous character with the formation of slit-shaped pores arising from the stacking of crystal particles. The specific surface area values (BET) of samples W1 and W2 were $22.30 \mathrm{~m}^{2} / \mathrm{g}$ and $4.48 \mathrm{~m}^{2} / \mathrm{g}$. The total pore volume values were $0.035 \mathrm{~cm}^{3} / \mathrm{g}$ and $0.006 \mathrm{~cm}^{3} / \mathrm{g}$, respectively (Table 4). The determined CEC and AEC values for samples W1 and W2 are also listed in Table 4. Theoretically, the higher the ion-exchange capacity of the sample, the larger the amount of anions or cations retained by ion-exchange, which means simpler to desorb. Comparing both samples, sample W1 was characterised by higher cation and anion exchange capacity values.

Table 4. Textural testing results and CEC, AEC results for samples W1 and W2.

\begin{tabular}{|c|c|c|c|c|c|c|c|}
\hline Sample & $\begin{array}{c}\mathbf{B E T} \\
{\left[\mathbf{m}^{2} / \mathbf{g}\right]}\end{array}$ & $\begin{array}{c}\text { BJH } \\
{\left[\mathbf{m}^{2} / \mathbf{g}\right]}\end{array}$ & $\begin{array}{c}\text { Single point } \\
\text { adsorption } \\
{\left[\mathbf{c m}^{3} / \mathbf{g}\right]}\end{array}$ & $\begin{array}{c}\text { Adsorption } \\
\text { average } \\
{[\mathbf{n m}]}\end{array}$ & $\begin{array}{c}\text { BJH } \\
\text { Adsorption } \\
{[\mathbf{n m}]}\end{array}$ & $\begin{array}{c}\text { CEC } \\
{[\mathbf{m e q} /} \\
\mathbf{1 0 0 g}]\end{array}$ & $\begin{array}{c}\text { AEC } \\
{[\mathbf{m e q} /} \\
\mathbf{1 0 0 g}]\end{array}$ \\
\hline $\mathrm{W} 1$ & 22.30 & 18.47 & 0.0350 & 6.3 & 7.64 & 6.07 & 33.79 \\
\hline $\mathrm{W} 2$ & 4.48 & 3.81 & 0.0061 & 5.4 & 6.48 & 3.67 & 18.06 \\
\hline
\end{tabular}

\subsection{Materials after autoclaving}

Figure 3 demonstrates the diffractograms of materials after synthesis. XRD analysis allowed identification of the following in the studied materials: in sample W1A: chabazite, gismondite, mullite, thomsonite, tobermorite, quartz; whereas in sample W2A: chabazite, melilite, mullite, sodalite, thomsonite and quartz. Chabazite, gismondite, thomsonite, sodalite belong to the zeolite group. These materials may be regarded as proper, expected synthesis products [30]. Other synthesis products are tobermorite, a hydrothermal alteration product of calcium carbonate occurring in the substrate of synthesis and melilite, a product of reaction between silica and alkali compounds from initial samples and $2 \mathrm{M} \mathrm{NaOH}$, respectively. Other components, like mullite or quartz are unreacted reagents occurring in the starting samples.
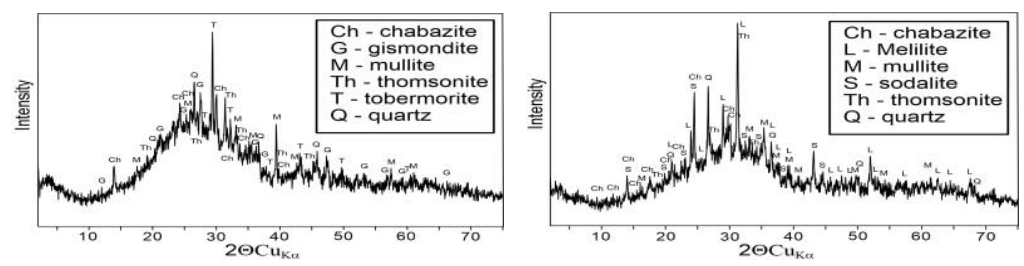

Fig. 3. X-ray diffraction pattern of samples: W1A (left) and W2A (right).

Figure. 4 (a-d) present SEM images of zeolite forms obtained as a result of hydrothermal synthesis from the studied waste samples in the autoclave. The morphology of these materials is totally different from that of the starting materials (Fig. 2). As a result of the synthesis, zeolite forms were obtained of chiefly spherical shape, placed on the surface of ash and slag particles. Large amounts of unreacted and amorphous fractions are also visible.

The synthesis products (W1A, W2A) show a similar type of isotherm and hysteresis loop of type $\mathrm{H} 3$ as in the case of the initial sample. However, we observed an increase in the SBET $\left(25.42 \mathrm{~m}^{2} / \mathrm{g}\right.$ for $\mathrm{W} 1 \mathrm{~A}$ and $16.79 \mathrm{~m}^{2} / \mathrm{g}$ for $\left.\mathrm{W} 2 \mathrm{~A}\right)$, and the total pore volume $\left(0.038,0.027 \mathrm{~cm}^{3} / \mathrm{g}\right.$ respectively) indicates that the synthesis processes had a significant influence on the textural parameters (Table 5). In general, the synthesis products are characterised by an increase in the $\mathrm{S}_{\mathrm{BET}}$ and $\mathrm{V}_{\text {tot }}$ compared with the starting samples. Comparison of CEC and AEC results for samples W1 and W1A (Tables 4 and 5), as well as 
W2 and W2A (Tables 4 and 5) shows that the autoclaving process affected advantageously ion-exchange properties of samples W1A and W2A. The cation exchange capacity for sample W1A increased threefold in comparison with sample W1, and for sample W2A, it rose twice in comparison with sample W2. The anion exchange capacity did not change significantly in the case of samples W1A and W2A in comparison with samples W1 and W2.
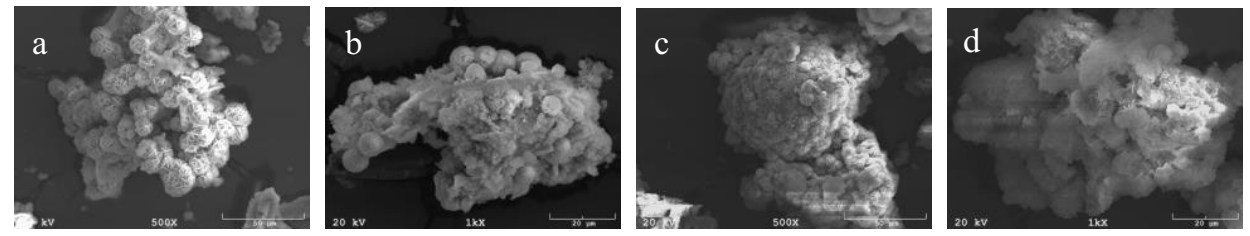

Fig. 4. SEM images of sample W1A (a ,b). Magnification 500x and 1000x. SEM images of sample W2A (c ,d). Magnification 500x and 1000x.

Table 5. Results of textural studies and CEC, AEC results for samples W1A and W2A.

\begin{tabular}{|c|c|c|c|c|c|c|c|}
\hline Sample & $\begin{array}{c}\mathbf{B E T} \\
{\left[\mathbf{m}^{2} / \mathbf{g}\right]}\end{array}$ & $\begin{array}{c}\mathbf{B J H} \\
{\left[\mathbf{m}^{2} / \mathbf{g}\right]}\end{array}$ & $\begin{array}{c}\text { Single point } \\
\text { adsorption } \\
{\left[\mathbf{c m}^{3} / \mathbf{g}\right]}\end{array}$ & $\begin{array}{c}\text { Adsorption } \\
\text { average } \\
{[\mathbf{n m}]}\end{array}$ & $\begin{array}{c}\text { BJH } \\
\text { Adsorption } \\
{[\mathbf{n m}]}\end{array}$ & $\begin{array}{c}\text { CEC } \\
{[\mathbf{m e q} /} \\
\mathbf{1 0 0 g}]\end{array}$ & $\begin{array}{c}\text { AEC } \\
{[\mathbf{m e q} /} \\
\mathbf{1 0 0 g}]\end{array}$ \\
\hline $\mathrm{W} 1 \mathrm{~A}$ & 25.42 & 17.93 & 0.0377 & 5.9 & 8.15 & 18.90 & 39.10 \\
\hline $\mathrm{W} 2 \mathrm{~A}$ & 16.79 & 13.18 & 0.0273 & 6.5 & 8.27 & 6.25 & 27.28 \\
\hline
\end{tabular}

\section{Conclusions}

The paper presents the results concern the change of physicochemical properties due to alkaline autoclaving. Based on the results obtained it was found that:

Post-processing waste from the waste incineration plants under study is useful for the production of zeolites in hydrothermal alkaline activation. Treatment of the waste from incineration plants in alkaline media leads to a change in the morphology of these materials and the formation of such zeolite forms as: chabazite, gismondite, thomsonite and sodalite.

The waste samples, with the EWC code $190111^{*}$ - Bottom ash and slag containing dangerous substances, subjected to autoclaving had different mineral composition, morphology and different cation and anion exchange capacities compared with the initial waste samples (raw material, starting/base material). In the case of the autoclaving process, based on the assessment of morphology and chemical composition, as well as the BET specific surface area, it was found that better results were obtained for waste sample W1A.

In the autoclaving process it is possible to obtain material with BET specific surface area values exceeding $25 \mathrm{~m}^{2} / \mathrm{g}$. Such materials may be used as sorbents.

XRD studies carried out demonstrated that in the autoclaving process, beside zeolite materials, the following were also obtained: tobermorite, a hydrothermal alteration product of calcium carbonate that occurs in the substrate of synthesis and melilite, a product of reaction between silica and alkali compounds from initial samples and $2 \mathrm{M} \mathrm{NaOH}$, respectively.

The analysis of SEM images revealed that in the case of coarse grained slag, zeolite structures are formed on the surface of particles, which is why it is necessary to grind/mill them in order to improve the efficiency.

The authors would like to express their gratitude to the National Centre for Research and Development and the National Fund for Environmental Protection and Water Management for supporting this work with the grant GEKON1/05/213240/35/2015. 


\section{References}

1. J. Łowkis, R. Jagiełło R., K. Kaczmarski, M. Surowiec, Ochr. Środ. 3-4 (1994)

2. W. Mokrosz, Inż. Chem. Proc. 25, 1327 (2004)

3. M. Łach, J. Mikuła, M. Hebda, J. Therm. Anal. Calorim. 125, 3 (2016)

4. Ch. H. K. Lam, A. W. M. Ip, J. P. Barford, G. McKay, Sustainability. 2,7 (2010)

5. T. Armbruster, M. E. Gunter, Mineral. and Geochem. 45 (2001)

6. A. Chica, Chem. Eng. 2013 (2013)

7. R. Aiello, G. Giordano, F. Testa, 142, Studies in Surface Science and Catalysis (2002)

8. K. L. Chang, W. H. Shih, Ind. Eng. Chem. Res. 37 (1998)

9. G. C. Hollman, G. Steenbruggen, M. Janssen-Jurkovicova, Fuel. 78 (1999)

10. M. Inada, Y. Eguchi, N. Enomoto, J. Hojo, Fuel. 84 (2005)

11. A. Derkowski, W. Franus, E. Beran, A. Czimerova A. Powder Technol. 166 (2006)

12. F. Fotovat, H. Kazemian, M. Kazemeini M. Mat. Res. Bul. 44, 2 (2009)

13. C. Belviso, F. Cavalcante, S. Fiore, Waste Manag. 30 (2010)

14. W. Franus, M. Wdowin, Environ. Monit. Assess. 186 (2014)

15. A. Grela, M. Hebda, M. Łach, J. Mikuła, Micro. Meso. Mat. 220 (2016)

16. A. Grela, M. Łach, J. Mikuła, M. Hebda, J. Therm. Anal. Calorim. 123, 2 (2016)

17. G. Yang, T. Y. Yang, J. Hazard. Mat. 62 (1998)

18. M. Michihiro, T. Chikashi, M. Matsuda, J. Am. Ceram. Soc. 85, 7 (2002)

19. R. P.̃a Penilla, A. G. Bustos, S. G. 〜i Elizalde, J. Am. Ceram. Soc. 86, 9 (2003)

20. T. Chikashi, M. Matsuda, Matsuda M., M. Michihiro, J. Ceram. Soc. 114, 2 (2006)

21. M. Sallam, R. P. Carnahan, A. Zayed, S. Sunol, 16th Ann. North Americ. Waste Energ. Conf. (2008)

22. Y.W. Chiang, K. Ghyselbrecht, R. M. Santos, B. Meesschaert, J. A. Martens, Catal. Today. 190 (2012)

23. Y. S. Shim, Y. K. Kim, S. H. Kong, S. W. Rhee, W. K. Lee, Waste Manag. 23 (2003)

24. V.K. Gupta, I. Ali; V.K. Saini; T. Van Gerven, B. D. Van Bruggen, Ind. Eng. Chem. Res. 44 (2005)

25. Y. Tao, H. Kanoh, L. Abrams, K. Kaneko, Chem. Rev. 106 (2006)

26. J. Iqra, M. Faryal, R. Uzaira, T. Noshaba, Mat. Scien. Eng. 60 (2014)

27. J. Rodziewicz, A. Mielcarek, I. Kłodowska, W. Janczukowicz, E. Choińska-Żurek, A. Wolter, Inż. Eko. 48 (2016)

28. A. Grela, T. Bajda, Inż. Eko. 19 (2017) (to be published)

29. T. Pająk, Roczn. PZH. 47 (1996)

30. M. Łach, D. Mierzwiński, J. Mikuła, Inż. Eko. 18 (2017) 